\title{
Control of Endophytic Frankia Sporulation by Alnus Nodule Metabolites
}

\author{
Hay Anne-Emmanuelle, , ${ }^{1,2}$ Boubakri Hasna, ${ }^{1,2}$ Buonomo Antoine, ${ }^{1,2}$ Rey Marjolaine, ${ }^{1,2}$ \\ Meiffren Guillaume, ${ }^{1,2}$ Cotin-Galvan Laetitia, ${ }^{1,2}$ Comte Gilles, ${ }^{1,2}$ and Herrera-Belaroussi Aude ${ }^{1,2}$ \\ ${ }^{1}$ PRES Université de Lyon, F-69361, Lyon, France and Université Lyon 1, F-69622, Villeurbanne, France; and ${ }^{2}$ Laboratoire \\ Ecologie Microbienne, UMR 5557 CNRS-Lyon1, Villeurbanne
}

Accepted 6 January 2017.

\begin{abstract}
A unique case of microbial symbiont capable of dormancy within its living host cells has been reported in actinorhizal symbioses. Some Frankia strains, named $\mathrm{Sp}+$, are able to sporulate inside plant cells, contrarily to $\mathrm{Sp}$ - strains. The presence of metabolically slowed-down bacterial structures in host cells alters our understanding of symbiosis based on reciprocal benefits between both partners, and its impact on the symbiotic processes remains unknown. The present work reports a metabolomic study of $\mathrm{Sp}+$ and Sp- nodules (from Alnus glutinosa), in order to highlight variabilities associated with in-planta sporulation. A total of 21 amino acids, 44 sugars and organic acids, and 213 secondary metabolites were detected using UV and mass spectrometricbased profiling. Little change was observed in primary metabolites, suggesting that in-planta sporulation would not strongly affect the primary functionalities of the symbiosis. One secondary metabolite (M27) was detected only in Sp+ nodules. It was identified as gentisic acid 5-O- $\boldsymbol{\beta}$-D-xylopyranoside, previously reported as involved in plant defenses against microbial pathogens. This metabolite significantly increased Frankia in-vitro sporulation, unlike another metabolite significantly more abundant in Sp-nodules [M168 = (5R)-1,7-bis-(3,4-dihydroxyphenyl)heptane-5- $O$ - $\beta$-D-glucopyranoside]. All these results suggest that the plant could play an important role in the Frankia ability to sporulate in planta and allow us to discuss a possible sanction emitted by the host against less cooperative $\mathrm{Sp}+$ symbionts.
\end{abstract}

Bacterial sporulation is a complex process resulting in the production of metabolically dormant cells_-or spores_-generally established to escape from nutritionally local conditions unfavorable to growth (Dworkin and Shah 2010). In soil, many bacterial populations spend part of their lives as spores to deal with environmental assaults. Among the most studied, Bacillus subtilis forms remarkably resistant endospores (e.g., to heat, desiccation, radiation, and chemical insult) in response to nutrient starvation, Streptomyces spp. differentiate, in the latter stages of their life cycle, chains of conidispores from aerial hyphae. In addition to temporal escape, spores can also be spatially relocated (via wind, water, living hosts) to favorable environments for

Corresponding author: A. Herrera-Belaroussi; Telephone: +(33) 472448 200; Fax: +(33) 426234 468; E-mail: aude.herrera-belaroussi@univ-lyon1.fr

*The $e$-Xtra logo stands for "electronic extra" and indicates that three supplementary data files are published online.

This article is in the public domain and not copyrightable. It may be freely reprinted with customary crediting of the source. The American Phytopathological Society, 2017. germination and vegetative growth (Nicholson et al. 2000). Bacterial sporulation, therefore, represents a highly successful strategy for survival and spatial dispersion of bacterial life. However, a unique case of endophytic symbionts able to sporulate inside host plant cells has been reported in some Frankia strains. Though endosymbionts, which benefit from a highly favorable habitat for their development and trophic interactions with their hosts (Torrey 1987; Schwintzer 1990), these strains produce sporangiospores with respiration rates 10 -fold lower than those for vegetative hyphae (Krumholz et al. 2003). Observing such sporulation directly within host cells is, thus, quite unexpected in a symbiotic context.

The actinobacteria Frankia are able to establish symbiotic associations with actinorhizal plants (e.g., members of genera Alnus and Casuarina), resulting in root nodules in which carbohydrates provided by the host plant are exchanged for nitrogen supplied by the bacteria. In this model, clear differences in microbial partner functional traits have been found, manifested as different types of nodules (van Dijk 1978; van Dijk and Merkus 1976). All available cultured Frankia strains form both vesicles (nitrogen-fixation site) and sporangiospores within sporangia under some cultural conditions. However, in the nodule, two types of strains have been described: $\mathrm{Sp}+$ strains (spore-positive), forming numerous spores within host plant cells, contrarily to Sp- strains, incapable of in-planta sporulation (Pozzi et al. 2015; Schwintzer 1990; Simonet et al. 1994; Torrey 1987). In Sp+ nodules, bacterial spore production inside plant cells is often massive (up to $10^{8}$ spores per gram of nodules) and occurs very early in nodule differentiation (Cotin-Galvan et al. 2016). Given that spore formation was generally described as an energyintensive and time-consuming process, it raises the question of the impact of in-planta bacterial sporulation on both partner interactions and the host influence on this microbial trait. Previous studies suggest that $\mathrm{Sp}+$ strains are less efficient in nitrogen fixation than $\mathrm{Sp}$ - strains (Houwers and Akkermans 1981; van Dijk 1984; Vandenbosch and Torrey 1984; Wheeler et al. 1986), which could affect carbon and nitrogen exchanges between plant and bacteria in $\mathrm{Sp}+$ nodules. $\mathrm{Sp}+$ strains may trade off their own multiplication by producing considerable sporangia in host cells at the expense of mutualistic behavior (Pozzi et al. 2015). This trade-off could result in sanctions from the host (Denison 2000; Kiers et al. 2003), leading to increased plant defense mechanisms in $\mathrm{Sp}+$ nodules compared with $\mathrm{Sp}$ - nodules. Important modifications in nodule primary and secondary metabolites can, thus, be hypothesized due to Frankia in-planta sporulation.

The purpose of the present study is to compare $\mathrm{Sp}+$ and $\mathrm{Sp}-$ nodule metabolome, in order to highlight modifications associated with in-planta sporulation, using UV and mass spectrometricbased metabolite profiling. This metabolomic approach aims to identify all metabolites in a cellular system and to monitor their 
quantities. In recent years, it has become a powerful tool to understand the complexity of plant systems, used for chemotaxonomy or metabolic change characterizations after biotic and abiotic stresses (Abdel-Farid et al. 2014; Allwood et al. 2010; Ott et al. 2003; Pedras and Zheng 2010), among available applications. Here, we compared the metabolomic diversity of a large number of $\mathrm{Sp}+$ and $\mathrm{Sp}$ - nodules from Alnus glutinosa (48 samples, including associated-root samples). These nodules were all collected from the field, in order to take into account the diversity of $\mathrm{Sp}+$ and $\mathrm{Sp}-$ Frankia strains associated with the A. glutinosa host (Pozzi et al. 2015). They came from six different alder stands previously described as "Sp+ sites" or "Sp- sites" (Pozzi et al. 2015). Chemical extractions were performed for all samples and resulting extracts were analyzed by ultra-high pressure liquid chromatography (UHPLC)/UV/ESI-MS (electrospray ionizationmass spectrometry) for secondary metabolite profiling. Analyses of amino acids were achieved through HPLC/UV, after online derivatization, and analyses of sugars and organic acids (SOA) through gas chromatographic (GC)/EI-QQQ (triple quadrupole). Discriminant metabolites between $\mathrm{Sp}+$ and $\mathrm{Sp}-$ nodules were characterized and tested for their effects on Frankia respiration and in-vitro sporulation.

\section{RESULTS}

A total of 48 samples (15 Sp+ nodule samples, $14 \mathrm{Sp}$ - nodule samples, and 19 associated-root samples) were successively extracted in methanol/water 50:50 (vol/vol) and pure methanol. The average dried extract quantity obtained from all samples was $29.61 \mathrm{mg} \pm 3.13 \mathrm{mg}$.
Characterization of discriminant primary metabolites between $\mathrm{Sp}+$ and $\mathrm{Sp}-$ nodules: SOA and amino acids.

The quality control (QC), made from 12 standard sugars and $5 \mu \mathrm{l}$ of each sample (as described below), and samples were analyzed by GC/EI-QQQ. A total of 44 SOA were detected from the total ion current (TIC) chromatogram (SOA 1 to 44 [Supplementary Data S1]). The principal component analysis (PCA) of sample metabolic profiles showed a slight discrimination between $\mathrm{Sp}+$ and $\mathrm{Sp}-$ nodules, with $\mathrm{PC} 1$ and $\mathrm{PC} 2$ scores of 12.19 and $7.62 \%$, respectively (Fig. 1A).

Sixteen SOA showed significant differences in their relative abundances (i.e., relative peak area calculated over the total area of the sample chromatogram, expressed as a percentage) between both types of nodules (Wilcoxon rank sum test, $P$ value $<$ 0.05). SOA 16 (glucose) was the most abundant metabolite in all nodule samples, with a relative abundance significantly higher in $\mathrm{Sp}+$ nodules. Among these $16 \mathrm{SOA}$, three were at least two times more abundant in $\mathrm{Sp}+$ nodules: SOA 9 (fumarate), SOA 23 (annotated as D-galactose), and SOA 33 (annotated as melezitose). Five SOA were at least two times more abundant in Sp- nodules: SOA 5 (annotated as xylopyranoside), SOA 12 (annotated as D-mannitol), SOA 32 (annotated as sucrose), SOA 38 (annotated as melibiose), and SOA 40 (unidentified) (Table 1). The most different metabolites between $\mathrm{Sp}+$ and $\mathrm{Sp}$ - nodules were metabolites annotated as D-galactose, 12-fold more abundant in Sp+ nodules, and D-mannitol and sucrose, sevenfold more abundant in $\mathrm{Sp}-$ nodules. In addition, the nodule mean relative abundance of each of the nine previously mentioned metabolites was computed from all nodule samples, including $\mathrm{Sp}+$ and $\mathrm{Sp}-$. Their root mean relative abundance was computed

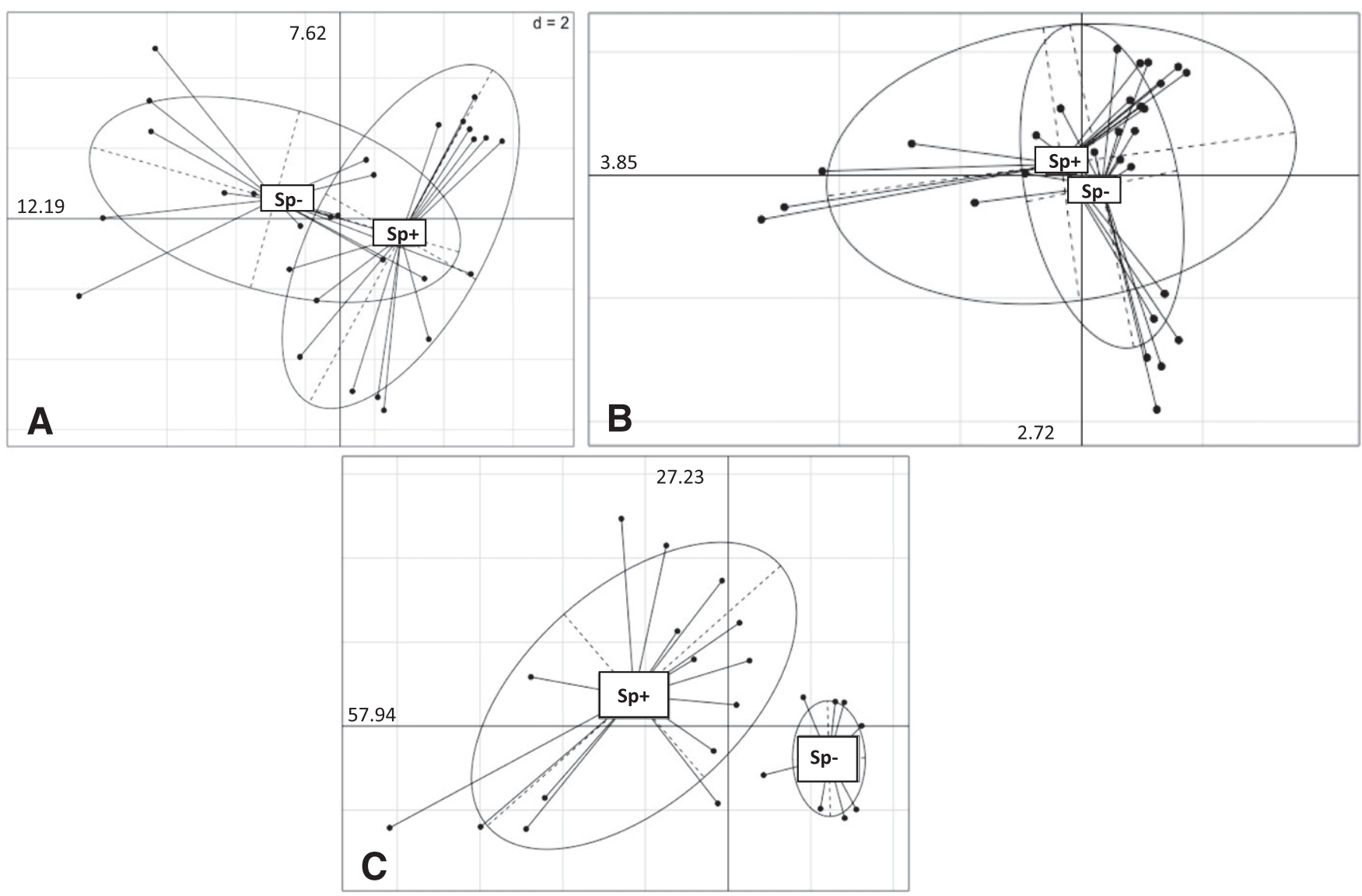

Fig. 1. Principal component analysis of $\mathrm{Sp}+$ (including Frankia spores in plant cells) and $\mathrm{Sp}$ - (without Frankia spores) nodule metabolic profiles for A, sugars and organic acids, $\mathbf{B}$, amino acids, and $\mathbf{C}$, secondary metabolites. Graphic representations were obtained with factors one and two. 
in a similar way for all associated-root samples (Table 1). Fumarate and metabolites annotated as D-galactose, melezitose, and melibiose showed a significantly higher abundance in nodules compared with roots (Wilcoxon rank sum test, $P$ value $<0.05$ ), with melibiose being up to 25 -fold more abundant. Glucose, in contrast, was significantly more abundant in roots.

A total of 21 amino acids were detected using LC/UV-DAD (diode array detection) analysis and were identified by comparison with the standard mixture (QC). Although the PCA did not show clear discrimination in nodule metabolic profiles according to their in-planta sporulation phenotype (Fig. 1B), three amino acids highlighted significantly different abundances between $\mathrm{Sp}+$ and $\mathrm{Sp}-$ nodules, namely, citrulline, arginine, and valine (Wilcoxon rank sum test, $P$ value $<0.05$ ). Citrulline and arginine were more abundant in $\mathrm{Sp}$ - nodules, while valine was more abundant in Sp+ nodules (Table 1). In addition, citrulline and arginine also showed a significantly reduced relative abundance in nodules compared with roots (Wilcoxon rank sum test, $P$ value $<0.05$ ).

\section{Characterization and identification of discriminant secondary metabolites between $\mathrm{Sp}+$ and $\mathrm{Sp}$ - nodules.}

The LC/UV/ESI-Q-TOF (quadrupole-time-of-flight) chromatograms of all 48 samples led to the detection of $213 \mathrm{sec}-$ ondary metabolites (M1 to M213). The PCA of these metabolites showed a strong discrimination between $\mathrm{Sp}+$ and $\mathrm{Sp}-$ nodules, with PC1 and PC2 scores of 57.94 and $25.23 \%$, respectively (Fig. 1C). A total of 114 secondary metabolites significantly varied in their relative abundances between both types of nodules (Wilcoxon rank sum test, $P$ value $<0.05)$. In addition to the 114,57 metabolites were at least two times more abundant in $\mathrm{Sp}+$ nodules compared with $\mathrm{Sp}$ - nodules and vice versa for 12 metabolites (the remaining 45 metabolites showed ratios lower than 2 between their mean relative abundances in $\mathrm{Sp}+$ and $\mathrm{Sp}$ - nodules and were considered of less interest in this study).

Only secondary metabolites with mean relative abundances higher than $1 \%$ were considered abundant enough to attempt purification and identification. A total of six metabolites were selected, four among 57 for Sp+ nodules (M27, M92, M137, and M171) and two among 12 for Sp- nodules (M168 and M180) (Table 2). Only metabolites M27 and M168 were successfully purified from $\mathrm{Sp}+$ and $\mathrm{Sp}-$ nodules, respectively. M27 was specific to $\mathrm{Sp}+$ nodules (meaning totally absent from roots and $\mathrm{Sp}$ - nodules). Its nuclear magnetic resonance (NMR) and MS spectral data analyses and results comparison with database led to the identification of gentisic acid 5- $O$ - $\beta$-D-xylopyranoside (Nassar et al. 2003) (white amorphous powder, calculated $\mathrm{C}_{12} \mathrm{H}_{14} \mathrm{O}_{8} 286.068870$ uma) (Fig. 2A). M168 was significantly more abundant in nodules compared with roots (Wilcoxon rank sum test, $P$ value $\left.=3.38 \mathrm{e}^{-4}\right)($ Table 2$)$ and, following NMR and MS, was identified as (5R)-1,7-bis-(3,4-dihydroxyphenyl)heptane-5- $O$ - $\beta$-D-glucopyranoside (Lee et al. 2000) (white amorphous powder, calculated $\mathrm{C}_{25} \mathrm{H}_{34} \mathrm{O}_{10}$ 494.215200) (Fig. 2B).

It is noticeable that the metabolite M132 was largely UVdominant (at $280 \mathrm{~nm}$ ) in all extract metabolite profiles (roots and nodules), with more than $62.72 \%$ of mean relative abundance. Although this metabolite was not discriminant between $\mathrm{Sp}+$ and $\mathrm{Sp}-$ nodules, it was successfully purified and identified as oregonin [(5S)-1,7-bis-(3,4-dihydroxyphenyl)-heptane-3one-5- $O-\beta$-D-xylopyranoside] (Kuroyanagi et al. 2005) (white amorphous powder, calculated $\mathrm{C}_{24} \mathrm{H}_{30} \mathrm{O}_{10} 478.183900$ uma) by NMR and MS spectral data analyses (Fig. 2C) .

\section{Effects of nodule extracts and metabolites on Frankia ACN14a in-vitro respiration and sporulation.}

$\mathrm{Sp}+$ and $\mathrm{Sp}-$ nodule total extracts were tested on Frankia ACN14a INT (iodo-nitro-tetrazolium) respiration at three different concentrations $(0.3,3$, and $30 \mu \mathrm{g} / \mathrm{ml})$. Three days after inoculation, both types of extracts showed a significantly positive effect on respiration at the highest concentration $(30 \mu \mathrm{g} / \mathrm{ml})$ compared with the control without nodule extract (Tukey's honest significant difference [HSD] test, $P$ value $<0.05$ ) (Fig. 3A and B). Bacterial respiration was also significantly higher in the presence of $\mathrm{Sp}+$ nodule extract at a concentration of $3 \mu \mathrm{g} / \mathrm{ml}$ (Tukey's HSD test, $P$ value $=9.042 \mathrm{e}^{-3}$ ) compared with the control (Fig. 3A). Ten days after inoculation, both $\mathrm{Sp}+$ and $\mathrm{Sp}$ - nodule extracts significantly decreased bacterial lethality at the highest concentration (optical density of 0.25 and 0.33 , respectively, compared with 0.09 for the control; Tukey's HSD test, $P$ value $<0.05$ ). A significant (Tukey's HSD test, $P$ value $=3.574 \mathrm{e}^{-3}$ ) and similar effect was only observed for $\mathrm{Sp}-$ nodule extract 7 days after inoculation.

Purified secondary metabolites M27 and M168 were also tested on Frankia ACN14a INT respiration at $0.1,1$, and $10 \mu \mathrm{M}$.

Table 1. Discriminant primary metabolites (sugars, organic acids, and amino acids) between Sp+ (with Frankia spores in plant cells) and Sp- (without Frankia spores in plant cells) nodules and roots

\begin{tabular}{|c|c|c|c|c|c|c|}
\hline \multirow[b]{2}{*}{ Compound } & \multirow[b]{2}{*}{$\mathbf{R t}^{\mathbf{a}}$} & \multicolumn{2}{|c|}{$\begin{array}{l}\text { Nodule relative mean } \\
\text { abundance }(\%)^{\mathbf{b}}\end{array}$} & \multirow[b]{2}{*}{$\mathrm{Sp}+/ \mathrm{Sp}-$ ratio $(P \text { value })^{\mathrm{c}}$} & \multirow[b]{2}{*}{ N/R ratio $(P \text { value })^{d}$} & \multirow[b]{2}{*}{ Database annotation $(\%)^{\mathrm{e}}$} \\
\hline & & $\mathrm{Sp}+$ & Sp- & & & \\
\hline SOA9 & 11.93 & 1.20 & 0.28 & $4.29\left(1.7 \mathrm{e}^{-5}\right)$ & $15.75\left(1.13 \mathrm{e}^{-6}\right)$ & Fumarate $(100 \%)$ \\
\hline SOA16 & 17.10 & 18.28 & 14.13 & $1.29\left(9.41 \mathrm{e}^{-3}\right)$ & $0.70\left(9.35 \mathrm{e}^{-6}\right)$ & Glucose $(100 \%)$ \\
\hline SOA23 & 21.75 & 2.07 & 0.17 & $12.18\left(1.405 \mathrm{e}^{-5}\right)$ & $4.81\left(6.38 \mathrm{e}^{-4}\right)$ & D-galactose (72\% NIST) \\
\hline SOA33 & 25.71 & 6.42 & 2.21 & $2.90\left(5.097 \mathrm{e}^{-6}\right)$ & $1.52\left(3.48 \mathrm{e}^{-3}\right)$ & Melezitose (86\% AMDIS) \\
\hline SOA5 & 7.04 & 0.42 & 1.57 & $0.27\left(1.514 \mathrm{e}^{-3}\right)$ & $2.67(>0.05)$ & Xylopyranoside (93\% NIST) \\
\hline SOA12 & 14.55 & 0.40 & 2.95 & $0.14\left(5.211 \mathrm{e}^{-4}\right)$ & $0.67(>0.05)$ & D-mannitol (98\% AMDIS) \\
\hline SOA32 & 24.98 & 0.54 & 3.93 & $0.14\left(1.955 \mathrm{e}^{-2}\right)$ & $0.93(>0.05)$ & Sucrose (91\% AMDIS) \\
\hline SOA38 & 30.87 & 4.95 & 12.13 & $0.41\left(7.273 \mathrm{e}^{-3}\right)$ & $25.62\left(1.06 \mathrm{e}^{-8}\right)$ & Melibiose (68\% NIST) \\
\hline SOA40 & 31.49 & 0.57 & 2.39 & $0.24\left(4.551 \mathrm{e}^{-3}\right)$ & $2.53(>0.05)$ & Non-identified \\
\hline Citrulline & 8.06 & 60.62 & 72.90 & $0.83\left(7.903 \mathrm{e}^{-3}\right)$ & $0.90\left(4.00 \mathrm{e}^{-2}\right)$ & - \\
\hline Arginine & 8.52 & 0.50 & 1.84 & $0.27\left(4.281 \mathrm{e}^{-4}\right)$ & $0.49\left(3.35 \mathrm{e}^{-3}\right)$ & - \\
\hline Valine & 11.76 & 4.52 & 2.69 & $1.68\left(6.805 \mathrm{e}^{-3}\right)$ & $1.57\left(5.04 \mathrm{e}^{-3}\right)$ & - \\
\hline
\end{tabular}

${ }^{\mathrm{a}} \mathrm{Rt}=$ retention time in minutes.

b Relative peak areas reported to the total area of chromatograms.

${ }^{c}$ Ratios between relative abundances in $\mathrm{Sp}+$ and $\mathrm{Sp}$ - nodules. $P$ values were obtained by comparing mean relative abundances in both nodule types with Wilcoxon rank sum statistical tests.

${ }^{\mathrm{d}}$ Ratios between relative abundances in nodules $(\mathrm{N})$ and roots $(\mathrm{R})$ (including all $\mathrm{Sp}+$ and $\mathrm{Sp}$ - nodule samples for $\mathrm{N}$ and all associated-root samples for $\mathrm{R}$ ). $P$ values were obtained by comparing $\mathrm{N}$ and $\mathrm{R}$ mean relative abundances with Wilcoxon rank sum statistical tests.

e For metabolite annotation, we used the National Institute of Standards and Technology (NIST) database and AMDIS (automated mass spectral deconvolution and identification system) software. The percent identification is given in parentheses (100\% indicates when identification was confirmed by comparison with standards). 
M27 at $1 \mu \mathrm{M}$ and M168 at $10 \mu \mathrm{M}$ induced a significantly greater bacterial respiration 3 days after inoculation, as compared with the control (Tukey's HSD test, $P$ value $=3.085 \mathrm{e}^{-2}$ and $2.344 \mathrm{e}^{-2}$, respectively) (Fig. 3C and D). The commercial gentisic acid (2,5dihydroxybenzoic acid without the glycosyl moiety, compared with M27) was also tested at the same concentrations but did not show any significant effect on Frankia respiration (Fig. 3E). Finally, no effects of purified metabolites on bacterial respiration were observed 7 and 10 days after inoculation.

Total nodule extracts $(0.3,3$, and $30 \mu \mathrm{g} / \mathrm{ml})$ and purified metabolites $(0.1,1$, and $10 \mu \mathrm{M})$ were also tested on Frankia ACN14a sporulation 10 days after inoculation (Fig. 4). While $\mathrm{Sp}+$ nodule extract significantly inhibited sporangia production only at the highest concentration $(30 \mu \mathrm{g} / \mathrm{ml}), \mathrm{Sp}$ - nodule extract induced a significantly lower sporulation at all concentrations, as compared with the control (Tukey's HSD test, $P$ value < 0.05) (Fig. 4A). Regarding purified secondary metabolites, an opposite effect was observed between M27 and M168 at the highest concentration $(10 \mu \mathrm{M})$ (Fig. 4B). M27 significantly induced bacterial sporulation (Tukey's HSD test, $P$ value = $\left.8.860 \mathrm{e}^{-3}\right)$, compared with the control, while M168 significantly inhibited sporangia production $\left(P\right.$ value $\left.=1.949 \mathrm{e}^{-2}\right)$. The commercial gentisic acid significantly increased sporulation at $0.1 \mu \mathrm{M}$ compared with the control (Tukey's HSD test, $P$ value $=$ $\left.6.972 \mathrm{e}^{-4}\right)$ and tended to inhibit at the highest concentration (Tukey's HSD test, $P$ value $\left.=7.186 \mathrm{e}^{-2}\right)($ Fig. $4 \mathrm{~B})$.

Total carbon and nitrogen content in $\mathrm{Sp}+$ and $\mathrm{Sp}$ - nodules.

In addition to metabolite profiling, total carbon and nitrogen nodule contents were also compared between $\mathrm{Sp}+$ and $\mathrm{Sp}-$ nodules. $\mathrm{Sp}+$ nodules showed a significantly lower carbon content compared with $\mathrm{Sp}$ - nodules (47.80 against $50.50 \%$ in $\mathrm{Sp}$ - nodules, analysis of variance [ANOVA], $P$ value $=2.297 \mathrm{e}^{-2}$ ). No significant difference was observed in nitrogen content between both types of nodules.

\section{DISCUSSION}

Plants and microorganisms are capable of symbiotic sustainable associations often based on trophic complementarities. These interactions lead to reciprocal enhancement in the fitness of both partners involving a reciprocal cost. To our knowledge, $\mathrm{Sp}+$ Frankia strains are the only case of microbial symbiont capable of dormancy within the plant host cells. The presence of metabolically slowed down bacterial structures in host cells, therefore, alters our perception of symbiosis based on the reciprocal benefit concept (in bacteria, sporulation is usually considered as a survival strategy under adverse conditions). The impact of in-planta microbial sporulation on symbiotic processes is still unknown. Therefore, the present study aimed to compare the metabolomic diversity of a large number of $\mathrm{Sp}+$ and $\mathrm{Sp}$ - field nodules in order to highlight variabilities associated with inplanta sporulation. In this context, we focused on primary and secondary metabolite profiling, using HPLC/UV after online derivatization (for amino acids), GC/EI-QQQ (for OAS), and UHPLC/UV/ESI-MS (for secondary metabolites) analyses.

$\mathrm{Sp}+$ and $\mathrm{Sp}-$ nodules shared more than $70 \%$ of detected primary metabolites (amino acids, OAS), suggesting that the bacterial in-planta sporulation would not strongly affect the primary functionalities in Frankia-Alnus symbiosis. No major difference could be detected in organic acids involved in nitrogen fixation or assimilation (e.g., glutamic acid, 2-oxoglutarate, and derivatives

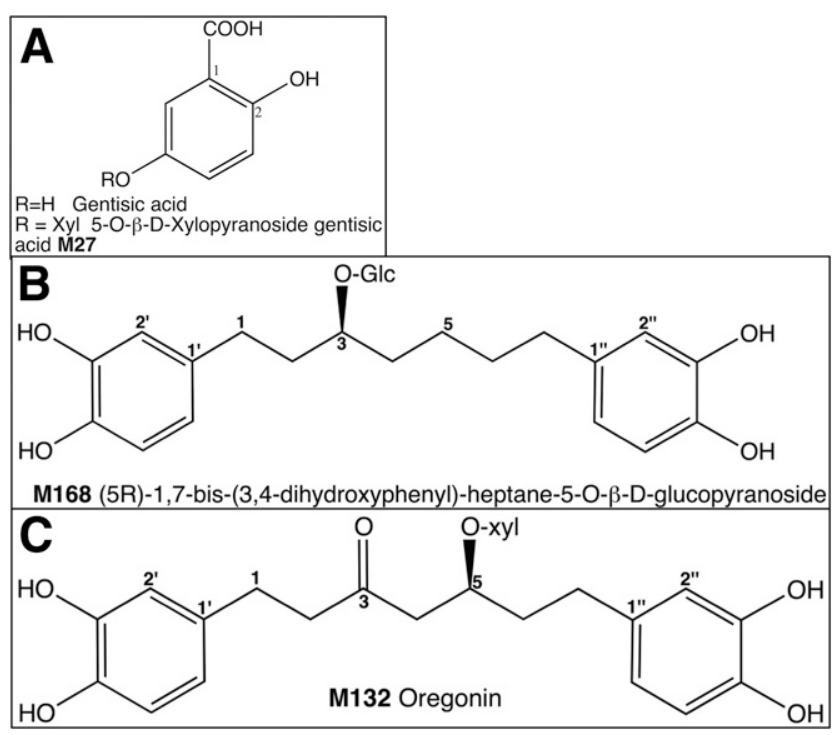

Fig. 2. Chemical structures of purified secondary metabolites A, M27, B, M168, and C, M132.

Table 2. Discriminant secondary metabolites between $\mathrm{Sp}+$ nodules, $\mathrm{Sp}-$ nodules, and roots ${ }^{\mathrm{a}}$

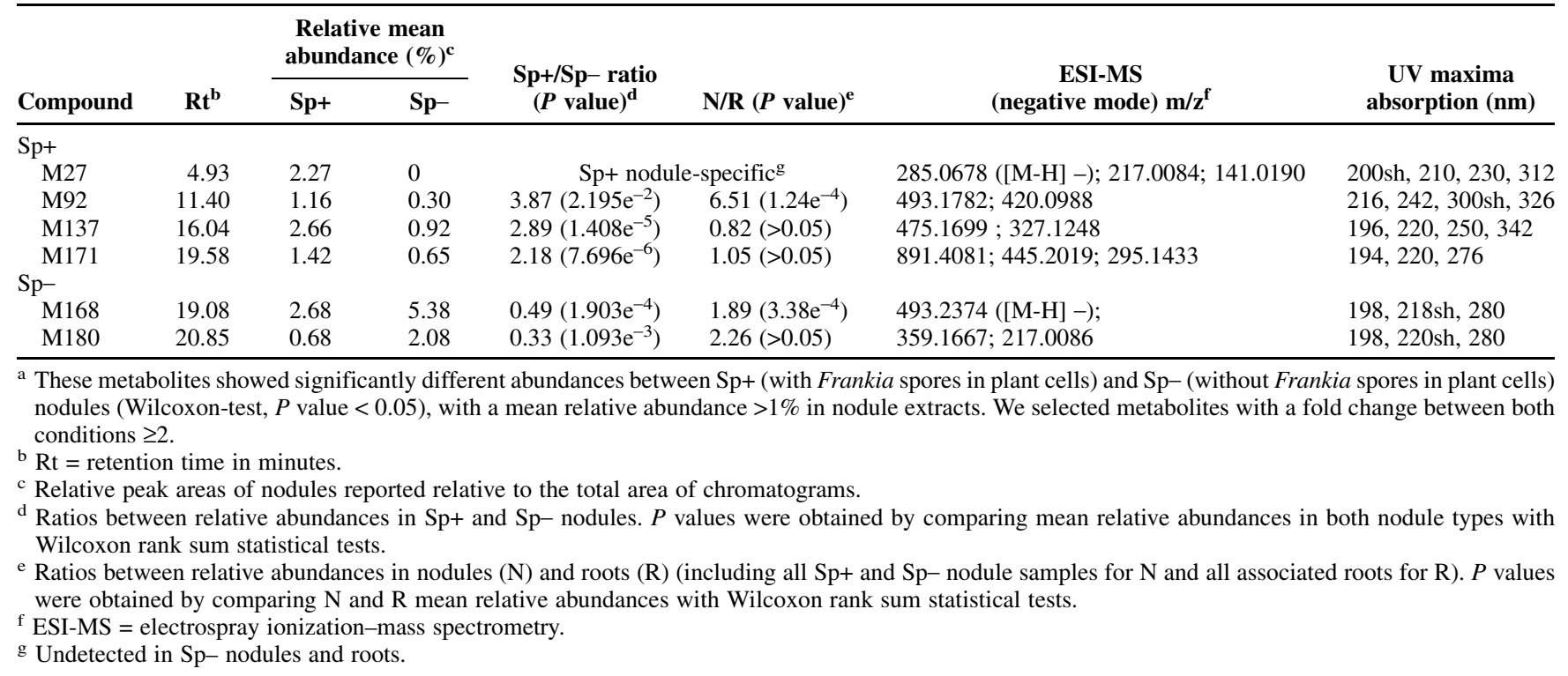


[Schultz and Benson 1990]). However, significant differences between $\mathrm{Sp}+$ and $\mathrm{Sp}$ - nodules were observed for two amino acids, citrulline and arginine. In the nodule, fixed nitrogen can be stored as an amide (i.e., asparagine) or as urea-cycle amino acids (i.e., citrulline or arginine) (Berry et al. 2011). In the present study, citrulline was the most abundant amino acid in nodule and root extracts (more than $60 \%$ of the total amino acids content). This observation is strongly consistent with previous studies suggesting that, in Alnus, the arginine pathway including citrulline predominates and that citrulline is the major soluble nitrogenous compound in nodules and other plant tissues (Berry et al. 2011; Bollard 1957; Brooks and Benson 2016; Leaf et al. 1958; McClure et al. 1983; Miettinen and Virtanen 1952; Schubert et al. 1981). Additionally, both citrulline and arginine were significantly more abundant in roots as compared with nodules, suggesting their role in nitrogen compound export from nodules.

When considering both amino acid amounts in $\mathrm{Sp}+$ and $\mathrm{Sp}-$ nodules, a significantly lower concentration was observed in
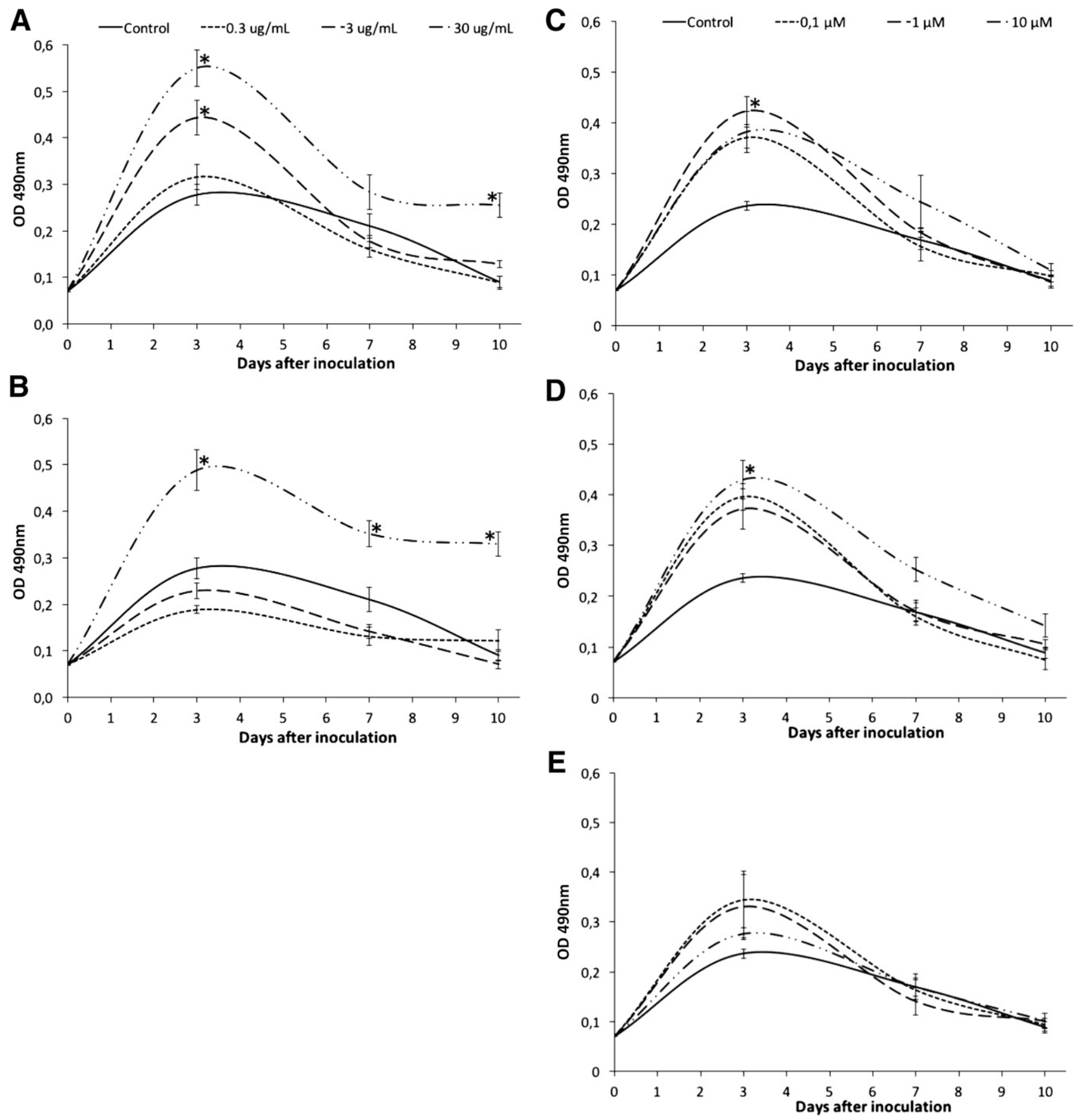

Fig. 3. Effect of A, Sp+ (with Frankia spores in plant cells) and B, Sp- (without Frankia spores in plant cells) and C, pure compounds M27, D, M168, and E, gentisic acid on Frankia ACN14a respiration rates. Frankia respiration was measured using tetrazolium/formazan iodo-nitro-tetrazolium, as described by Carro et al. (2016). Controls were made in the presence of absolute ethanol/water 75:25 (\% vol/vol) (A and B) or absolute ethanol/water 50:50 (\% vol/vol) $(\mathrm{C}, \mathrm{D}$ and E), used to dilute nodule extracts or pure compounds, respectively. Error bars indicate standard deviations. An asterisk (*) indicates significant differences compared with the control condition (Tukey's honest significant difference test, $P$ value $<0.05$ ). 
$\mathrm{Sp}+$ nodules compared with $\mathrm{Sp}-$, suggesting either a higher nitrogen export from $\mathrm{Sp}+$ nodules, less storage of nitrogen amino acids, or both. This hypothesis could be explained by either i) a lower ability of $\mathrm{Sp}+$ strains to fix nitrogen, as proposed in the literature (Houwers and Akkermans 1981; van Dijk 1984; Vandenbosch and Torrey 1984; Wheeler et al. 1986) or ii) a higher arginine and citrulline uptake by $\mathrm{Sp}+$ strains (e.g., to produce sporangia), or both. In the other well-known sporulating bacteria model Clostridium, arginine is metabolized to citrulline, required to produce spores (Perkins and Tsuji 1962).

In contrast to primary metabolites, $50 \%$ of secondary metabolites were found significantly different between $\mathrm{Sp}+$ and $\mathrm{Sp}-$ nodules. Both plant and bacteria are able to produce secondary metabolites, generally known to be involved in diverse functions including, but not limited to, defense against biotic or abiotic stresses and communication with other organisms (Demain and Fang 2001; Mazid et al. 2011). The origin of these metabolites is, therefore, hard to elucidate, since they were present in nodules, resulting from plant and bacteria interactions. A bacterial origin of discriminant secondary metabolites between $\mathrm{Sp}+$ and $\mathrm{Sp}-$ nodules could not be excluded. Indeed, bioinformatics analyses of Frankia genomes revealed an unexpected number of secondary metabolic biosynthesis gene clusters (Udwary et al. 2011). However, in our study, metabolite purification and NMR analyses led to the identification of compounds usually found in plants. The secondary metabolite M132, largely dominant in all nodule extracts (more than 60\%), was, indeed, identified as oregonin [(5S)-1,7-bis-(3,4-dihydroxyphenyl)-heptane-3-one-5$O-\beta$-D-xylopyranoside], previously reported from different tissues of Alnus species, such as Alnus rubra bark (Sati et al. 2011). Another diarylheptanoid was found at significantly higher levels in Sp- nodules, the metabolite M168, identified as (5R)-1,7-bis(3,4-dihydroxyphenyl)-heptane-5- $O-\beta$-D-glucopyranoside (Lee et al. 2000). Diarylheptanoids are very common in several organs of Alnus spp., such as bark, leaves, or fruits (Choi 2013; Gonzalez-Laredo and Karchesy 1997; Kang et al. 2004; Yadav and Gupta 2014), although, as far as we know, they have never been described in nodules. These types of compounds were previously observed to be responsible for different activities, such as antibacterial and antioxidant (Ilic-Tomic et al. 2016; Ponomarenko et al. 2014; Saxena et al. 1995). They could be produced by the host plant as a defense-like response to control bacteria in the rhizosphere, including pathogen and symbiotic microorganisms. The diarylheptanoid M168 is greatly interesting because of its abundance in nodules compared with roots, and particularly, in $\mathrm{Sp}-$ nodules. The host plant could control the invading symbiotic bacteria by producing this metabolite as a defense molecule. Plant defenses would also be required in the very close symbiotic rhizobia-legume system for optimal nodule functioning (Gourion et al. 2015). In Alnus nodules, the diarylheptanoid M168 metabolite could be produced in the nodule periderm (since several diarylheptanoids were isolated from bark, the metabolites could therefore be present in this tissue), although to date, there is no relevant indication on diarylheptanoids localization in $\mathrm{Sp}+$ and $\mathrm{Sp}$ - nodules.

Interestingly, we observed here that the diarylheptanoid M168 did not impact Frankia growth but inhibited Frankia in-vitro sporulation as well as total $\mathrm{Sp}$ - nodule extract (unlike $\mathrm{Sp}+$ nodule extract). This observation suggests that, in $\mathrm{Sp}-$ nodule extracts, some secondary metabolites emitted by the host plant could prevent the bacterial symbiont to sporulate, and this metabolic cocktail would be finely regulated to ensure that the bacteria remain metabolically active for plant benefit (in vegetative form to fix nitrogen).

The most important finding that emerges from this work is the secondary metabolite M27, the only metabolite among 213 detected, specific to $\mathrm{Sp}+$ nodules (not detected in roots and $\mathrm{Sp}$ - nodules). This metabolite was identified as gentisic acid 5-O- $\beta$-D-xylopyranoside (Nassar et al. 2003). It was previously described as a pathogen-inducible signal for activation of plant defenses in tomato and cucumber and was associated with systemic infections in compatible plant-pathogen interactions (Bellés et al. 1999; Fayos et al. 2006).

The "cheater" behavior of Sp+ Frankia strains (i.e., lessbeneficial endophyte that mimics the "genuine mutualists" without totally fulfilling its symbiotic obligations) was recently discussed by Pozzi et al. (2015). Sp+ strains would be less efficient in nitrogen fixing and less cooperative than $\mathrm{Sp}-$ strains by diverting part of the plant energy resources for the production of many sporangia (Pozzi et al. 2015; Schwintzer 1990; Torrey 1987). In Rhizobia-legume symbioses, such behavior induces host plant defense mechanisms to sanction the cheater bacterial symbionts (Kiers et al. 2003). Under this hypothesis, gentisic acid 5- $O-\beta$-D-xylopyranoside M27 could be produced in the nodule by the host plant as a sanction against $\mathrm{Sp}+$ Frankia strains. However, the involvement of $\mathrm{Sp}+$ strains in M27 production can actually not be excluded, since the high ability of Frankia spp. to synthetize many different secondary
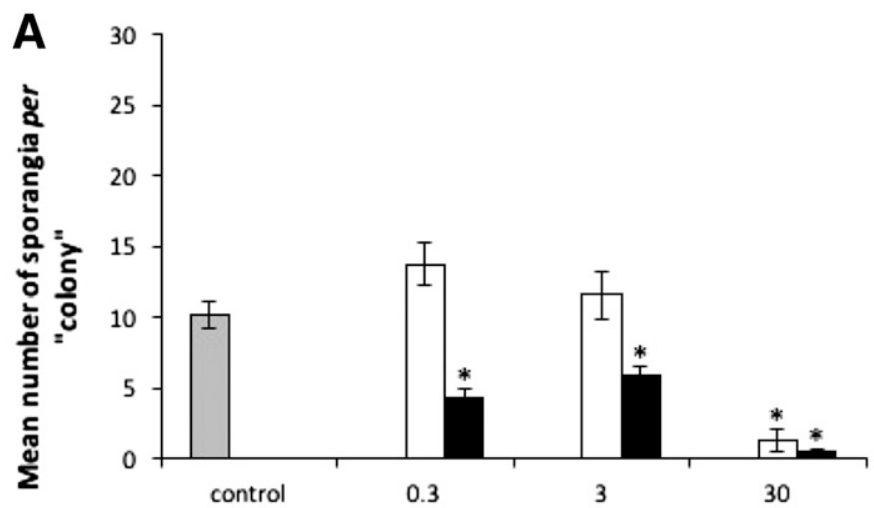

Nodule extract final concentration $(\mu \mathrm{g} / \mathrm{mL})$

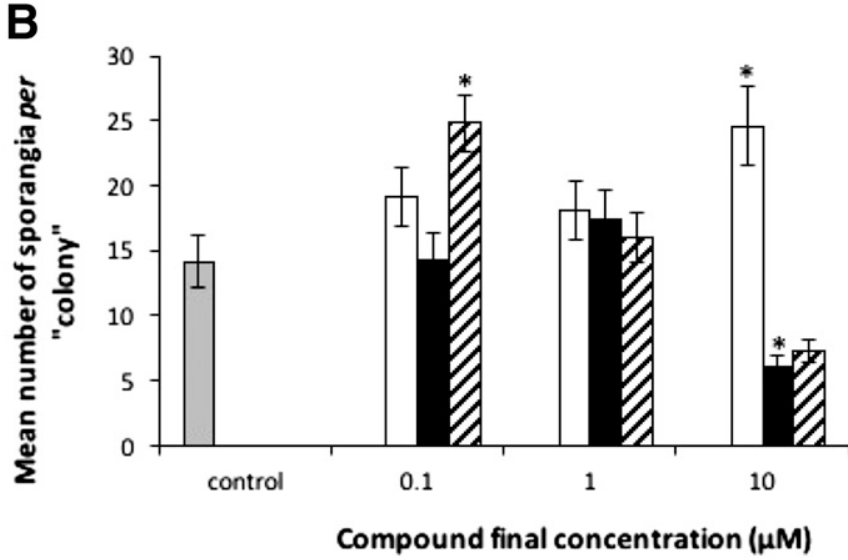

Fig. 4. Effect of A, nodule extracts and $\mathbf{B}$, pure compounds on Frankia ACN14a sporulation. In A, white bars $=\mathrm{Sp}+$ (able to sporulate inside plant cells), black bars $=\mathrm{Sp}-$ (unable to sporulate inside plant cells). Controls were made in the presence of absolute ethanol/water 75:25 (vol/vol), used to dilute nodule extracts. In B, white bars = M27, black bars = M168, and hatched bars = gentisic acid. Controls were made in presence of absolute ethanol/water 50:50 (vol/vol), used to dilute pure compounds. Error bars indicate standard deviations. An asterisk (*) indicates significant differences compared with the control condition (Tukey's honest significant difference test, $P$ value $<0.05$ ). 
metabolites, as previously discussed. A plant-bacteria coproduction could also be possible. Furthermore, at this stage, we still ignore where this metabolite is actually produced in nodule tissues. Host infected cells full of Sp+ Frankia spores could be a likely location, which might be confirmed using matrix-assisted laser desorption-imaging mass spectrometry (MALDI-IMS), recently used to investigate metabolites in Medicago truncatula nodules and roots (Gemperline et al. 2015; Ye et al. 2013).

Our study also demonstrated a stimulating effect of this metabolite on Frankia spp. in-vitro sporulation, without any negative effect on bacterial respiration rate (the bacterial respiration rate was even better in the presence of M27 under some conditions). Interestingly, the gentisic acid, for which xyloside substituent is lacking, compared with M27, showed a different effect on Frankia sporulation. These results suggest the specific stimulation effect of gentisic acid 5- $O-\beta$-D-xylopyranoside M27, at high concentrations, on bacterial respiration and sporulation. This effect raises the question of a possible adaptation of Frankia $\mathrm{Sp}+$ to bypass the host plant sanction by producing more sporangia. In the current state of knowledge, it remains difficult to understand whether Frankia in-planta sporulation could be a cause or a consequence of specific plant defense metabolites in Sp+ nodules.

Under the cheater hypothesis, another form of sanctions against $\mathrm{Sp}+$ strains could also be a limited supply of carbohydrates to the nodule, as suggested by the significantly lower carbon content in $\mathrm{Sp}+$ nodules compared with $\mathrm{Sp}-$ nodules. It is also worth noting that, despite the small difference in primary metabolite content between both nodule types, one major change was observed for the metabolite SOA 32, sevenfold less abundant in Sp+ nodules, and chemically close to sucrose. The latter is the form of photoassimilate most commonly used in long-distance transport in the plant phloem (Lemoine 2000). Its lower abundance in Sp+ nodules could mean that they are less supplied with carbon sources by the host plant than $\mathrm{Sp}-$ nodules or, simply, reflect the higher ability of $\mathrm{Sp}+$ strains to rapidly metabolize these carbohydrates. In addition, more complex polymers were found in $\mathrm{Sp}+$ nodules, like fumarate (organic acid) and melezitose (trisaccharide), while a disaccharide, melibiose, was significantly more abundant in $\mathrm{Sp}-$ nodules. A recent study illustrated that fumarate induced longer and lower Frankia respiration dynamics, compared with Frankia spp. preferred carbon sources (Carro et al. 2016). The higher presence of complex compounds in $\mathrm{Sp}+$ nodules could suggest a possible way for the host plant to slow down the dissemination of sporulating — and potentially less cooperative—symbionts.

\section{Conclusion.}

In the present study, we conducted, for the first time, to our knowledge, the metabolite profiling of $\mathrm{Sp}+$ and $\mathrm{Sp}$ - nodules, in order to highlight differences associated with Frankia in-planta sporulation in SOA, amino acids, and secondary metabolites. More changes between both nodule types were globally observed in secondary metabolites, as compared with primary metabolites. Two secondary metabolites analyzed as discriminant were isolated and characterized, i.e., the gentisic acid 5-O- $\beta-\mathrm{D}-$ xylopyranoside (M27), specifically produced in $\mathrm{Sp}+$ nodules, and the (5R)-1,7-bis-(3,4-dihydroxyphenyl)-heptane-5- $O$ - $\beta$-Dglucopyranoside (M168), more abundant in Sp- nodules. Both metabolites remind defense molecules emitted by the host plant but their respective effects on Frankia sporulation were totally opposite. While the metabolite isolated from $\mathrm{Sp}$ - nodules (M168) inhibited Frankia in-vitro sporulation (as well as $\mathrm{Sp}$ - total extract), a significantly higher production of spores was observed in the presence of M27. These results suggested that the host plant could play an important role in the Frankia ability to sporulate in planta. It could exert control over potentially less cooperative $\mathrm{Sp}+$ symbionts through specific secondary metabolites and, to a lesser extent, by regulating the flow of photosynthates provided to the nodule. Promising approaches such as MALDI-IMS could be tested to investigate the nodule localization and to quantify the different metabolites associated with in-planta sporulation. Finally, further genomic and transcriptomic analyses of both plant and bacteria might be helpful to decipher genes involved in metabolic pathways of metabolites of interest and their expression in $\mathrm{Sp}+$ versus $\mathrm{Sp}-$ nodules and roots.

\section{MATERIALS AND METHODS}

\section{Alnus glutinosa $\mathrm{Sp}+$ and $\mathrm{Sp}-$ field nodule and associated-root sampling.}

All nodules and roots were collected between September and October 2012 from six Alnus glutinosa stands, previously described as "Sp+ sites" (three sites) or "Sp- sites" (three sites) in Pozzi et al. (2015) (Table 3). Three different trees were randomly selected per site and, for each of them, a minimum of three nodules were collected with associated roots. All nodules were phenotypically and genetically analyzed to confirm Sp+ or Spphenotype, as described by Pozzi et al. (2015). All collected material was stored at $-80^{\circ} \mathrm{C}$ before being freeze-dried (Christ Alpha 1-4 freeze dryer).

In our experiments, a nodule sample is defined as a pool of three nodules collected on three different trees (one nodule per tree) coming from the same site, which represents a minimum of three nodule samples per site. Similar sampling was done for associated roots (at least three pooled root samples were also made per site). Each sample, whether nodule or associated root, was made from $150 \mathrm{mg}$ of freeze-dried material, was crushed to very fine dry powder (Retsch TissueLyser II), and was kept in liquid nitrogen, until the first extraction. A total of 48 samples (15 Sp+ nodule samples, $14 \mathrm{Sp}$ - nodule samples, and 19 associated-root samples [Table 3]) were extracted.

\section{Metabolic extraction.}

Each nodule and associated-root sample was processed as described as follows. A first metabolic extraction was performed in $1 \mathrm{ml}$ of methanol/water 50:50 ( $\mathrm{vol} / \mathrm{vol})$. Dissolution was expedited by vortexing (Heidolph Top-mix 94323) and sonication (Bransonic Ultrasonic cleaner 2510E-DTH), followed by $15 \mathrm{~min}$ of centrifugation at $15,870 \times g$. The resulting supernatant was kept as a first extract (E1). The remaining pellet was used for the second metabolic extraction, performed in $1 \mathrm{ml}$ of methanol (100\%) and was followed by a dissolution similarly expedited as for E1, to get the second extract (E2). Both extracts E1 and E2 were mixed and dried (CentriVap concentrator $\mathrm{LABCONCO}$ ) before lyophilization. They were stored at $-20^{\circ} \mathrm{C}$, prior to chromatographic analyses.

\section{Chromatographic analyses.}

Sugars and organic acids analysis by GC/EI-QQQ. Dried extracts underwent two derivatization reactions with Hydroxylamine

Table 3. Origins of $\mathrm{Sp}+$ and $\mathrm{Sp}$ - nodule (with and without Frankia spores in plant cells, respectively) samples

\begin{tabular}{lclc}
\hline $\begin{array}{l}\text { Nodule } \\
\text { phenotype }\end{array}$ & $\begin{array}{c}\text { Site } \\
\text { reference }\end{array}$ & \multicolumn{1}{c}{ Location $^{\mathbf{a}}$} & $\begin{array}{c}\text { Number } \\
\text { of } \mathbf{~ N} \text { and } \mathbf{R}^{\mathbf{b}}\end{array}$ \\
\hline Sp+ & S1+ & Le Tremblay, Bourget-du-Lac (\#28) & $4 \mathrm{~N}, 3 \mathrm{R}$ \\
& S2+ & Thury (pop. V, \#3) & $4 \mathrm{~N}, 3 \mathrm{R}$ \\
& S3+ & Miribel (\#17) & $7 \mathrm{~N}, 3 \mathrm{R}$ \\
Sp- & S1- & Arandon (\#21) & $4 \mathrm{~N}, 4 \mathrm{R}$ \\
& S2- & Le Grand-Lemps (\#22) & $3 \mathrm{~N}, 3 \mathrm{R}$ \\
& S3- & Le Blanchet, Bourget-en-Huile (\#27) & $7 \mathrm{~N}, 3 \mathrm{R}$ \\
\hline
\end{tabular}

\footnotetext{
a Site numbers as referenced by Pozzi et al. (2015) are in parentheses.

b Numbers of nodules $(\mathrm{N})$ or roots $(\mathrm{R})$ pooled and collected from three different trees per site.
} 
hydrochloride and N,O-bis(trimethylsilyl) trifluoroacetamide (BSTFA) in order to transform all SOA into a more volatile form that is suitable with the GC analysis. Extracts were first dissolved at $10 \mathrm{mg} / \mathrm{ml}$ in a $30-\mathrm{mg} / \mathrm{ml}$ hydroxylamine $\mathrm{HCl}$ solution and were incubated $30 \mathrm{~min}$ at $80^{\circ} \mathrm{C}$. BSTFA was then added at $300 \mu \mathrm{l} / \mathrm{ml}$, before incubating $10 \mathrm{~min}$ at $80^{\circ} \mathrm{C}$.

$\mathrm{GC}$ analyses were performed for derivatized samples within $24 \mathrm{~h}$ after derivatization, using Agilent Technologies 7000A EITriple Quad, coupled with the 7890A GC system and Agilent $190915-433$ column (HP5-MS, $0.25 \mathrm{~mm} \times 30 \mathrm{~m} \times 0.25 \mu \mathrm{m}$ ) with helium as vector gas at a constant flow of $1 \mathrm{ml} / \mathrm{min}$. The inlet temperature was $290^{\circ} \mathrm{C}$ with a $20: 1$ split, and the temperature gradient $(35 \mathrm{~min})$ was as follows: $165^{\circ} \mathrm{C}$ for $3 \mathrm{~min} ; 165^{\circ} \mathrm{C}$ to $195^{\circ} \mathrm{C}$ at $2^{\circ} \mathrm{C}$ per min; $195^{\circ} \mathrm{C}$ to $290^{\circ} \mathrm{C}$ at $15^{\circ} \mathrm{C}$ per min, and $290^{\circ} \mathrm{C}$ to $300^{\circ} \mathrm{C}$ at $15^{\circ} \mathrm{C}$ per min. For mass analysis, electrons were accelerated to $70 \mathrm{eV}$. The gradient rinsing solvent was pyridine (solvent A) and isopropanol (solvent B). A QC containing $5 \mu$ of each derivatized sample and 12 standard sugars (Supplementary Data S2) was similarly analyzed.

Finally, TIC chromatograms were obtained with Agilent Mass Hunter qualitative analysis software.

Amino acid analysis by HPLC/DAD. Amino acid analyses were performed on the HPLC Agilent 1100 coupled with photodiode array detector, using C18 Eclipse AAA Agilent Zorbax column $(3.5 \mu \mathrm{m}, 4.6 \times 150 \mathrm{~mm})$. Two on-line derivatizations with o-phthalaldehyde (OPA) and fluorenylmethoxy chloroformate were applied. Samples were dissolved at $10 \mathrm{mg} / \mathrm{ml}$ in methanol/water 50:50 (vol/vol), along with a QC sample (mixture of $5 \mu \mathrm{l}$ of each sample and 24 standard amino acids [Supplementary Data S3]). The eluting solvents were: solvent A, $40 \mathrm{mM}$ $\mathrm{NaH}_{2} \mathrm{PO}_{4} \cdot 2 \mathrm{H}_{2} \mathrm{O}$ buffer, $\mathrm{pH} 7.8$, solvent $\mathrm{B}$, acetonitrile/ methanol/water 45:45:10 ( $\mathrm{vol} / \mathrm{vol} / \mathrm{vol})$. The $\mathrm{B}$ solvent gradient was as follows: $0 \%$ for $1.9 \mathrm{~min}$; 0 to $57 \%$ from 1.9 to $18.1 \mathrm{~min} ; 57$ to $100 \%$ from 18.1 to $18.6 \mathrm{~min}$; and $100 \%$ up to $26 \mathrm{~min}(2 \mathrm{ml} / \mathrm{min}$ constant flow) (Henderson et al. 2000). Chromatograms were analyzed at $338 \mathrm{~nm}$ for most amino acids, except for proline, which was detected at $262 \mathrm{~nm}$, with the Agilent LC 1100 offline ChemStation for LC and LC-MS analysis software.

Secondary metabolites analysis by HPLC/DAD/ESI-Q-TOF. Secondary metabolites were analyzed using Agilent Technologies accurate-mass Q-TOF LC-MS 6530, with the LC 1290 Infinity system and Poroshell 120 EC-C18 column $(3 \times 100 \mathrm{~mm}, 2.7 \mu \mathrm{m})$. Dried extracts were dissolved at $10 \mathrm{mg} / \mathrm{ml}$ in methanol/water 50 : $50(\mathrm{vol} / \mathrm{vol})$, were sonicated and were centrifuged to discard insoluble materiel. HPLC analyses were performed at $25^{\circ} \mathrm{C}$ with a flow-rate of $0.7 \mathrm{ml} / \mathrm{min}$, using acetic acid $0.4 \%$ in ultrapure water (solvent A) and acetonitrile (solvent B). The gradient was 98:2 $\mathrm{A} / \mathrm{B}$ (0 to $3 \mathrm{~min}$ ), $70: 30 \mathrm{~A} / \mathrm{B}$ (3 to $25 \mathrm{~min}$ ), and $0: 100 \mathrm{~A} / \mathrm{B}$ (25 to $33 \mathrm{~min}$ ), $98: 2 \mathrm{~A} / \mathrm{B}$ (33 $\mathrm{min}$ to $38 \mathrm{~min}$ ) (Table 4). Mass analyses were obtained in negative mode, with the nebulization gas (nitrogen) at a flow of 12 liters per minute and 40 psi pressure. The capillary tension was 3,000 V and gave ionization energy of 100 eV. A QC sample containing $5 \mu$ l of each sample was initially

Table 4. Gradient used for UPHLC/DAD/ESI-Q-TOFa analyses of secondary metabolites

\begin{tabular}{lcc}
\hline Time (min) & Solvent A $(\boldsymbol{\%})$ & Solvent B $\mathbf{( \% )}$ \\
\hline 0 & 98 & 2 \\
3 & 98 & 2 \\
25 & 70 & 30 \\
29 & 0 & 100 \\
33 & 0 & 100 \\
34 & 98 & 2 \\
38 & 98 & 2 \\
\hline
\end{tabular}

${ }^{a}$ Ultra-high pressure liquid chromatography diode array detection electrospray ionization-quadrupole-time-of-flight. analyzed and was replicated after every 10 samples. Chromatograms were explored at $280 \mathrm{~nm}$ with Mass Hunter qualitative analysis B.05.00 software.

\section{Metabolite profiling data treatment and statistical analyses.}

For each of the three chromatographic analyses (SOA, amino acids, and secondary metabolites), a preliminary work consisted in peak alignment between all samples, based on peak retention time. This work resulted in three metabolite profiling matrices, with samples in rows and absolute area $\left(\mathrm{A}_{\mathrm{abs}}\right)$ of detected metabolites within SOA, amino acids, or secondary metabolites chromatograms in columns. For each metabolite within a given sample, its relative peak area (i.e., relative abundance in the sample $=A_{\text {rel }}$ ) was calculated over the total area of the sample chromatogram $\left(\sum \mathrm{A}_{\mathrm{abs}}\right)$ as follows: $\% \mathrm{~A}_{\text {rel }}=$ $\mathrm{A}_{\mathrm{abs}} / \sum \mathrm{A}_{\mathrm{abs}} \cdot 100$.

PCA were made from these matrices in order to visualize the effect of the nodule sporulating phenotype on nodule metabolite profiles. The effect of nodule phenotype on metabolite relative abundances was also statistically tested, in order to highlight significantly different metabolites between $\mathrm{Sp}+$ and $\mathrm{Sp}$ - nodules. Statistical analyses were performed using R software version 2.15.3. Since relative abundance data were not normally distributed, Wilcoxon rank sum statistical tests were used. Among significantly different metabolites between both types of nodules, we applied a minimal fold-change threshold of 2, below which differential relative abundances between $\mathrm{Sp}+$ and $\mathrm{Sp}-$ nodules is unlikely to be of interest for any metabolite. We finally selected the most abundant metabolites (mean relative abundance in nodule samples $>1 \%$ ) to attempt purification.

\section{Identification of discriminating SOA.}

Discriminating SOA were annotated using the Fiehn database (AMDIS software) (Fiehn 2008) and National Institute of Standards and Technology (NIST02) database (MassHunter qualitative analysis B.05.00, Agilent Technologies software). When possible, comparisons with standards also allowed confirming metabolite identity.

\section{Purification and identification of discriminating secondary metabolites.}

Purification of M27 by semipreparative HPLC. A total of $208.2 \mathrm{mg}$ of $\mathrm{Sp}+$ nodule extract was submitted to semipreparative HPLC on a HP1100 system with a photodiode array detector (Agilent Technologies). The column used was Macherey-Nagel VP Nucleodur 100-5 C18ec (C18; $250 \times 10 \mathrm{~mm} ; 5 \mu \mathrm{m})$. HPLC analyses were performed at $40^{\circ} \mathrm{C}$ with a flow rate of $3.5 \mathrm{ml} / \mathrm{min}$, using acetic acid $0.4 \%$ in ultrapure water (solvent $\mathrm{A}$ ) and acetonitrile (solvent B) (Carlo Erba reagents). Ultrapure water, acetic acid, and acetonitrile were obtained from Direct-Q 5 UV (Merck Millipore), Carlo Erba Reagents, and VWR (Prolabo Hipersolv Chromanorm), respectively. The gradient was 95:5 A/B (0 to $3 \mathrm{~min}$ ), $75: 25 \mathrm{~A} / \mathrm{B}$ (3 to $23 \mathrm{~min}$ ), and 0:100 A/B (23 to $29 \mathrm{~min}$ ). Injected volume was $100 \mu \mathrm{l}$ of a $40-\mathrm{mg} / \mathrm{ml}$ solution of $\mathrm{Sp}+$ total extract in methanol. Detection of M27 was done at 280 and $320 \mathrm{~nm}$. Retention time for the M27 was $14.22 \mathrm{~min}$ and collection was done between 14 and $14.5 \mathrm{~min}$. The purification resulted in $2.0 \mathrm{mg}$ (dried weight) of M27 (6.9 $\mathrm{e}^{-3} \mathrm{~mol}$; yield $\left.1 \%\right)$. NMR analyses were then done in $\mathrm{CD}_{3} \mathrm{OD}$.

Purification of M132 and M168 by semipreparative HPLC. Both metabolites were purified from $170.0 \mathrm{mg}$ of total $\mathrm{Sp}$ nodule extracts. A liquid-liquid extraction was performed twice in $10 \mathrm{ml}$ of ultrapure water and $10 \mathrm{ml}$ of $\mathrm{CH}_{2} \mathrm{Cl}_{2}$, resulting in the organic phase EA (12.8 mg, dried weight). The aqueous layer was similarly partitioned in $10 \mathrm{ml}$ of ethyl acetate (Hipersolv Chromanorm, VWR Prolabo), resulting in the organic phase EB 
(27.3 mg, dried weight), and, finally, in $10 \mathrm{ml}$ of $\mathrm{n}$-butanol (Hipersolv Chromanorm, VWR Prolabo), resulting in the organic phase EC (39.1 mg, dried weight). The three organic phases were pooled to obtain ED (70.7 mg, dried weight) and were analyzed by semipreparative HPLC, using a HPLC 1100 system with a photodiode array detector. The column used was Macherey Nagel VP Nucleodur 100-5 C18ec $(\mathrm{C} 18 ; 250 \times 10 \mathrm{~mm} ; 5 \mu \mathrm{m})$. Analyses were performed at $40^{\circ} \mathrm{C}$ with a flow rate of $3.5 \mathrm{ml} / \mathrm{min}$, using acetic acid $0.4 \%$ in ultrapure water (solvent $\mathrm{A}$ ) and acetonitrile (solvent B) (Carlo Erba Reagents). The gradient was 80: $20 \mathrm{~A} / \mathrm{B}$ (0 to $3 \mathrm{~min}$ ), 61:39 A/B (3 to $21 \mathrm{~min}$ ), and $0: 100 \mathrm{~A} / \mathrm{B}$ (21 to $23 \mathrm{~min}$ ). Injected volume was $100 \mu \mathrm{l}$ of $20-\mathrm{mg} / \mathrm{ml} \mathrm{ED}$ in methanol/water 50:50 (vol/vol). Retention time for M132 was $10.72 \mathrm{~min}$ and collection was done at $280 \mathrm{~nm}$ between 10.45 and $10.85 \mathrm{~min}$. Retention time for M168 was $13.67 \mathrm{~min}$ and collection was done at $320 \mathrm{~nm}$ between 13.5 and $13.7 \mathrm{~min}$. The purification resulted in $2.0 \mathrm{mg}$ of M168 and $18.9 \mathrm{mg}$ of M132 (dried weights), yielding in 1.1 and $11.1 \%$, respectively (4.04 $10^{-6}$ and $3.95 \mathrm{e} 10^{-5} \mathrm{~mol}$, respectively).

Identification of M27, M132, and M168 by semipreparative HPLC. NMR spectra were recorded on a Brucker DRX 500 spectrometer (500 MHz for ${ }^{1} \mathrm{H}$ and $125 \mathrm{MHz}$ for ${ }^{13} \mathrm{C}$ ) in $\mathrm{CD}_{3} \mathrm{OD}$ as solvent (internal reference, tetramethylsilane). D4-methanol used for NMR analysis was from Magnisolv Merck (Darmstadt, Germany).

\section{Biological material, growth condition, and in-vitro tests of purified metabolites.}

The ACN14a Frankia strain (Normand and Lalonde 1982) was grown in liquid BAP (Murry et al. 1984) medium without ammonium (BAP-) under the same conditions described by Carro et al. (2016). Seven-day-old cultures with two induction steps in BAP- medium were made before in-vitro tests. M27 and M168 nodule purified metabolites and commercial gentisic acid (Sigma Aldrich) were solubilized in ethanol/water 50:50 (vol/vol) and were supplemented in Frankia ACN14a BAP- cultures at final concentrations of $0.1,1$, and $10 \mu \mathrm{M}$. Nodule extracts were solubilized in ethanol/water 75:50 and were supplemented in Frankia cultures at $0.3,3$, and $30 \mu \mathrm{g} / \mathrm{ml}$ at final concentration. Five replicates per condition were performed. Positive controls were also included with the same volume of solvent ethanol/water, $50: 50$ or $75: 50(\mathrm{vol} / \mathrm{vol})$, without purified metabolites or nodule extracts. The effects of M27, M168, M132, and Sp+/ Sp- nodule extracts were also tested on INT reduction, without Frankia cells in the reaction, in order to verify their redox properties. None of them reduced INT, confirming they did not affect Frankia respiration rates (data not shown). After 3, 7, and 10 days of growth, measures of respiration (using tetrazolium/formazan INT) and fixation (based on acetylene reduction) were performed as described by Carro et al. (2016). Sporangia production was also assessed after 10 days of culturing, using light microscopy (Nikon Eclipse E400). For this purpose, sporangia were enumerated for each tested condition, from at least 23 hyphae clusters-named colonies-randomly observed under the microscope. The mean number of sporangia per colony was computed. Since data were normally distributed, ANOVA and Tukey's HSD were used to compare effects of purified metabolites or nodule extracts on respiration, acetylene fixation, and sporulation (using $\mathrm{R}$ software version 2.15.3).

\section{Total carbon and nitrogen nodule content measurement.}

For each sampled tree, total carbon and nitrogen content of nodules were measured using a Flash EA1112 elemental analyzer (Thermo Fischer Scientific Inc.), following the procedure previously described by Grigulis et al. (2013) and Saccone et al. (2013), from 3 to $4 \mathrm{mg}$ of lyophilized and ground material. A total of eight $\mathrm{Sp}+$ and nine $\mathrm{Sp}-$ nodule samples were analyzed.
Since data were normally distributed, one-criterion ANOVA was made to test the effect of $\mathrm{Sp}+/ \mathrm{Sp}$ - nodule phenotype on carbon and nitrogen contents (using $\mathrm{R}$ software version 2.15.3).

\section{ACKNOWLEDGMENTS}

The authors thank F. Bellvert for his useful advice on experimental procedures as well as P. Fournier, J. Hamzaoui, and Z. Aziz for their help in experimental processes. We also thank the IBIO platform (UMR-CNRS 5557) for help in statistical analyses and B. Belaroussi for his careful proofreading of the manuscript. L. Cotin-Galvan was granted a doctoral fellowship by the Ministère de l'Enseignement Supérieur et de la Recherche (France) through the doctoral school Évolution, Écosystèmes, Microbiologie, Modélisation (ED341 E2M2; Lyon, France).

\section{LITERATURE CITED}

Abdel-Farid, I. B., Sheded, M. G., and Mohamed, E. A. 2014. Metabolomic profiling and antioxidant activity of some Acacia species. Saudi J. Biol. Sci. 21:400-408.

Allwood, J. W., Clarke, A., Goodacre, R., and Mur, L. A. J. 2010. Dual metabolomics: A novel approach to understanding plant-pathogen interactions. Phytochemistry 71:590-597.

Bellés, J. M., Garro, R., Fayos, J., Navarro, P., Primo, J., and Conejero, V. 1999. Gentisic acid as a pathogen-inducible signal, additional to salicylic acid for activation of plant defenses in tomato. Mol. Plant-Microbe Interact 12:227-235.

Berry, A. M., Mendoza-Herrera, A., Guo, Y.-Y., Hayashi, A., Persson, T., Barabote, R., Demchenko, K., Zhang, S., and Pawlowski, K. 2011. New perspectives on nodule nitrogen assimilation in actinorhizal symbioses. Funct. Plant Biol. 38:645-652.

Bollard, E. G. 1957. Translocation of organic nitrogen in the xylem. J. Biol. Sci. 10:292-301.

Brooks, J. M., and Benson, D. R. 2016. Comparative metabolomics of root nodules infected with Frankia sp. strains and uninfected roots from Alnus glutinosa and Casuarina cunninghamiana reflects physiological integration. Symbiosis 70:87-96

Carro, L., Persson, T., Pujic, P., Alloisio, N., Fournier, P., Boubakri, H., Pawlowski, K., and Normand, P. 2016. Organic acids metabolism in Frankia alni. Symbiosis 70:37-48.

Choi, S. E. 2013. Chemotaxonomic significance of oregonin in Alnus species. Asian J. Chem. 25:6989-6990.

Cotin-Galvan, L., Pozzi, A. C., Schwob, G., Fournier, P., Fernandez, M. P., and Herrera-Belaroussi, A. 2016. In-planta sporulation capacity enhances infectivity and rhizospheric competitiveness of Frankia strains. Microbes Environ. 31:11-18.

Demain, A. L., and Fang, A. 2001. The natural functions of secondary metabolites. Pages 1-39 in: History of Modern Biotechnology I. A. Fiechter, ed. Springer Berlin Heidelberg, Berlin.

Denison, R. F. 2000. Legume sanctions and the evolution of symbiotic cooperation by rhizobia. Am. Nat. 156:567-576.

Dworkin, J., and Shah, I. 2010. Exit from dormancy in microbial organisms. Nat. Rev. Microbiol. 8:890-896.

Fayos, J., Belles, J.M., Lopez-Gresa, M.P., Primo, J., and Conejero, V. 2006. Induction of gentisic acid 5-O- $\beta$-D-xylopyranoside in tomato and cucumber plants infected by different pathogens. Phytochemistry 67:142-148.

Fiehn, O. 2008. Extending the breadth of metabolite profiling by gas chromatography coupled to mass spectrometry. Trends Analyt. Chem. 27:261-269.

Gemperline, E., Jayaraman, D., Maeda, J., Ane, J. M., and Li, L. 2015. Multifaceted investigation of metabolites during nitrogen fixation in Medicago via high resolution MALDI-MS imaging and ESI-MS. J. Am. Soc. Mass Spectrom. 26:149-158.

Gonzalez-Laredo, R. F., and Karchesy, J. J. 1997. Structure and significance of natural diarylheptanoids. Rev. Latinoam. Quim. 25:62-70.

Gourion, B., Berrabah, F., Ratet, P., and Stacey, G. 2015. Rhizobiumlegume symbioses: The crucial role of plant immunity. Trends Plant Sci. 20:186-194.

Grigulis, K., Lavorel, S., Krainer, U., Legay, N., Baxendale, C., Dumont, M., Kastl, E., Arnoldi, C., Bardgett, R. D., Poly, F., Pommier, T., Schloter, M., Tappeiner, U., Bahn, M., and Clément, J. C. 2013. Relative contributions of plant traits and soil microbial properties to mountain grassland ecosystem services. J. Ecol. 101:47-57.

Henderson, J., Ricker, R., Bidlingmeyer, B., and Woodward, C. 2000. Rapid, accurate, sensitive and reproducible HPLC analysis of amino acids. Agilent Technologies, Technical Note 5980-1193E. 
Houwers, A., and Akkermans, A. 1981. Influence of inoculation on yield of Alnus glutinosa in the Netherlands. Plant Soil 61:189-202.

Ilic-Tomic, T., Sokovic, M., Vojnovic, S., Ciric, A., Veljic, M., Nikodinovic-Runic, J., and Novakovic, M. 2016. Diarylheptanoids from Alnus viridis ssp. viridis and Alnus glutinosa: Modulation of quorum sensing activity in Pseudomonas aeruginosa. Planta Med. Published online. 10.1055/s-0042-107674

Kang, H. M., Son, K. H., Yang, D. C., Han, D. C., Kim, J. H., Baek, N. I., and Kwon, B. M. 2004. Inhibitory activity of diarylheptanoids on farnesyl protein transferase. Nat. Prod. Res. 18:295-299.

Kiers, E. T., Rousseau, R. A., West, S. A., and Denison, R. F. 2003. Host sanctions and the legume-rhizobium mutualism. Nature 425:78-81.

Krumholz, G. D., Chval, M. S., McBride, M. J., and Tisa, L. S. 2003. Germination and physiological properties of Frankia spores. Plant Soil 254:57-67.

Kuroyanagi, M., Shimomae, M., Nagashima, Y., Muto, N., Okuda, A., Kawahara, N. T. N., and Sano, T. 2005. New diarylheptanoids from Alnus japonica and their antioxidative activity. Chem. Pharm. Bull. (Tokyo) 53:1519-1523.

Leaf, G., Gardner, I. C., and Bond, G. 1958. Observations on the composition and metabolism of the nitrogen-fixing root nodules of Alnus. J. Exp. Bot. 9:320-331.

Lee, M.-W., Park, M.-S., Jeong, D.-W., Kim, H-.H., and Toh, S.-H. 2000. Diarylheptanoids from the leaves of Alnus hirsuta Turcz. Med. Chem. Nat. Prod. 23:50-53.

Lemoine, R. 2000. Sucrose transporters in plants: Update on function and structure. BBA-Biomembranes 1465:246-262.

Mazid, M., Khan, T. A., and Mohammad, F. 2011. Role of secondary metabolites in defense mechanisms of plants. Biol. Med. 3:232-249.

McClure, P. R., Coker, G. T., and Schubert, K. R. 1983. Carbon dioxide fixation in roots and nodules of Alnus glutinosa. Plant Physiol. 71: 652-657.

Miettinen, J. K., and Virtanen, A. I. 1952. The free amino acids in the leaves, roots, and root nodules of the alder (Alnus). Physiol. Plant. 5: 540-557.

Murry, M., Fontaine, M., and Torrey, J. 1984. Growth kinetics and nitrogenase induction in Frankia sp. HFPArI3 grown in batch culture. Plant Soil 78: 61-78.

Nassar, M. I., Gaara, A. H., Marzouk, M. S., El-Din, E., and El-Khrisy, A. M. 2003. A new gentisic acid glycoside and C-glycosylflavones from Erythrina indica with the antioxidant activity evaluation. Bull. Fac. Pharm. Cairo Univ. 41:207-209.

Nicholson, W. L., Munakata, N., Horneck, G., Melosh, H. J., and Setlow, P. 2000. Resistance of Bacillus endospores to extreme terrestrial and extraterrestrial environments. Microbiol. Mol. Biol. Rev. 64:548572 .

Normand, P., and Lalonde, M. 1982. Evaluation of Frankia strains isolated from provenances of two Alnus species. Can. J. Microbiol. 28:11331142.

Ott, K. H., Aranibar, N., Singh, B., and Stockton, G. W. 2003. Metabonomics classifies pathways affected by bioactive compounds. Artificial neural network classification of NMR spectra of plant extracts. Phytochemistry 62:971-985

Pedras, M. S. C., and Zheng, Q. A. 2010. Metabolic responses of Thellungiella halophila/salsuginea to biotic and abiotic stresses: Metabolite profiles and quantitative analyses. Phytochemistry 71:581-589.

Perkins, W. E., and Tsuji, K. 1962. Sporulation of Clostridium botulinum II. Effect of arginine and its degradation products on sporulation in a synthetic medium. J. Bacteriol. 84:86-94.

Ponomarenko, J., Trouillas, P., Martin, N., Dizhbite, T., Krasilnikova, J., and Telysheva, G. 2014. Elucidation of antioxidant properties of wood bark-derived saturated diarylheptanoids: A comprehensive (DFTsupported) understanding. Phytochemistry 103:178-187.
Pozzi, A. C., Bautista-Guerrero, H., Nouioui, I., Cotin-Galvan, L., Pépin, R., Fournier, P., Menu, F., Fernandez, M. P., and Herrera-Belaroussi, A. 2015. In-planta sporulation phenotype: A major life-history trait to understand the evolution of Alnus-infective Frankia strains. Environ. Microbiol. 17: 3125-3138.

Saccone, P., Morin, S., Baptist, F., Bonneville, J.-M., Colace, M.-P., Domine, F., Faure, M., Geremia, R., Lochet, J., Poly, F., Lavorel, S., and Clément, J.-C. 2013. The effects of snowpack properties and plant strategies on litter decomposition during winter in subalpine meadows. Plant Soil 363:215-229.

Sati, S. C., Sati, N., and Sati, O. P. 2011. Bioactive constituents and medicinal importance of genus Alnus. Pharmacogn. Rev. 5:174-183.

Saxena, G., Farmer, S., Hancock, R. E. W., and Towers, G. H. N. 1995. Antimicrobial compounds from Alnus Rubra. Int. J. Pharmacognosy 33: 33-36.

Schubert, K. R., Coker, G. T., and Firestone, R. B. 1981. Ammonia assimilation in Alnus glutinosa and glycine max. Short-term studies using $\left[{ }^{13} \mathrm{~N}\right]$ ammonium. Plant Physiol. 67:662-665.

Schultz, N. A., and Benson, D. R. 1990. Enzymes of ammonia assimilation in hyphae and vesicles of Frankia sp. strain CpI1. J. Bacteriol. 172: 1380-1384.

Schwintzer, C. 1990. Spore-positive and spore-negative nodules. Pages 177-193 in: The Biology of Frankia and Actinorhizal Plants. N. S. Iacobellis, A. Collmer, S. W. Hutcheson, J. W. Mansfield, C. E. Morris, J. Murillo, N. W. Schaad, D. E. Stead, G. Surico, and M. Ullrich, eds. Kluwer Academic Academic Press, Dordrecht, The Netherlands.

Simonet, P., Bosco, M., Chapelon, C., Moiroud, A., and Normand, P. 1994 Molecular characterization of Frankia microsymbionts from sporepositive and spore-negative nodules in a natural alder stand. Appl. Environ. Microbiol. 60:1335-1341.

Torrey, J. 1987. Endophyte sporulation in root nodules of actinorhizal plants. Physiol. Plant. 70:279-288.

Udwary, D. W., Gontang, E. A., Jones, A. C., Jones, C. S., Schultz, A. W., Winter, J. M., Yang, J. Y., Beauchemin, N., Capson, T. L., Clark, B. R., Esquenazi, E., Eustaquio, A. S., Freel, K., Gerwick, L., Gerwick, W. H., Gonzalez, D., Liu, W. T., Malloy, K. L., Maloney, K. N., Nett, M., Nunnery, J. K., Penn, K., Prieto-Davo, A., Simmons, T. L., Weitz, S., Wilson, M. C., Tisa, L. S., Dorrestein, P. C., and Moore, B. S. 2011. Significant natural product biosynthetic potential of actinorhizal symbionts of the genus Frankia, as revealed by comparative genomic and proteomic analyses. Appl. Environ. Microbiol. 77:3617-3625.

van Dijk, C. 1978. Spore formation and endophyte diversity in root nodules of Alnus glutinosa (L.). New Phytol. 81:601-615.

van Dijk, C. 1984. Ecological aspects of spore formation in Frankia-Alnus symbiosis. Ph.D. thesis. University of Leiden, The Netherlands.

van Dijk, C., and Merkus, E. 1976. A microscopical study of the development of a spore-like stage in the life cycle of the root nodule endophyte of Alnus glutinosa (L.). New Phytol. 77:73-91.

Vandenbosch, K., and Torrey, J. 1984. Consequences of sporangial development for nodule function in root nodules of Comptonia peregrina and Myrica gale. Plant Physiol. 76:556-560.

Wheeler, C. T., Hooker, J. E., Crowe, A., and Berrie, A. M. M. 1986. The improvement and utilization in forestry of nitrogen fixation by actinorhizal plants with specific reference to Alnus in Scotland. Plant Soil 90:393-406.

Yadav, D., and Gupta, M. M. 2014. Simultaneous quantification of diarylheptanoids in Alnus nepalensis using a validated HPTLC Method. J. Chromatogr. Sci. 52:905-910.

Ye, H., Gemperline, E., Venkateshwaran, M., Chen, R., Delaux, P. M., Howes-Podoll, M., Ane, J. M., and Li, L. 2013. MALDI mass spectrometry-assisted molecular imaging of metabolites during nitrogen fixation in the Medicago truncatula-Sinorhizobium meliloti symbiosis. Plant J. 75:130-145. 